\title{
QSAR study for antifungal activity of coumarin derivatives
}

\section{Vesna Rastija ${ }^{a}$, Melita Lončarićb ${ }^{b}$ Maja Karnaša ${ }^{a}$ Karolina Vrandečića, Jasenka Čosića, Maja Molnar ${ }^{b}$}

${ }^{\text {a }}$ Faculty of Agrobiotechnical Sciences Osijek, Josip Juraj Strossmayer University of Osijek, 31000 Osijek, Croatia

${ }^{\mathrm{b}}$ Faculty of Food Faculty Osijek, Josip Juraj Strossmayer University, 31000 Osijek, Croatia

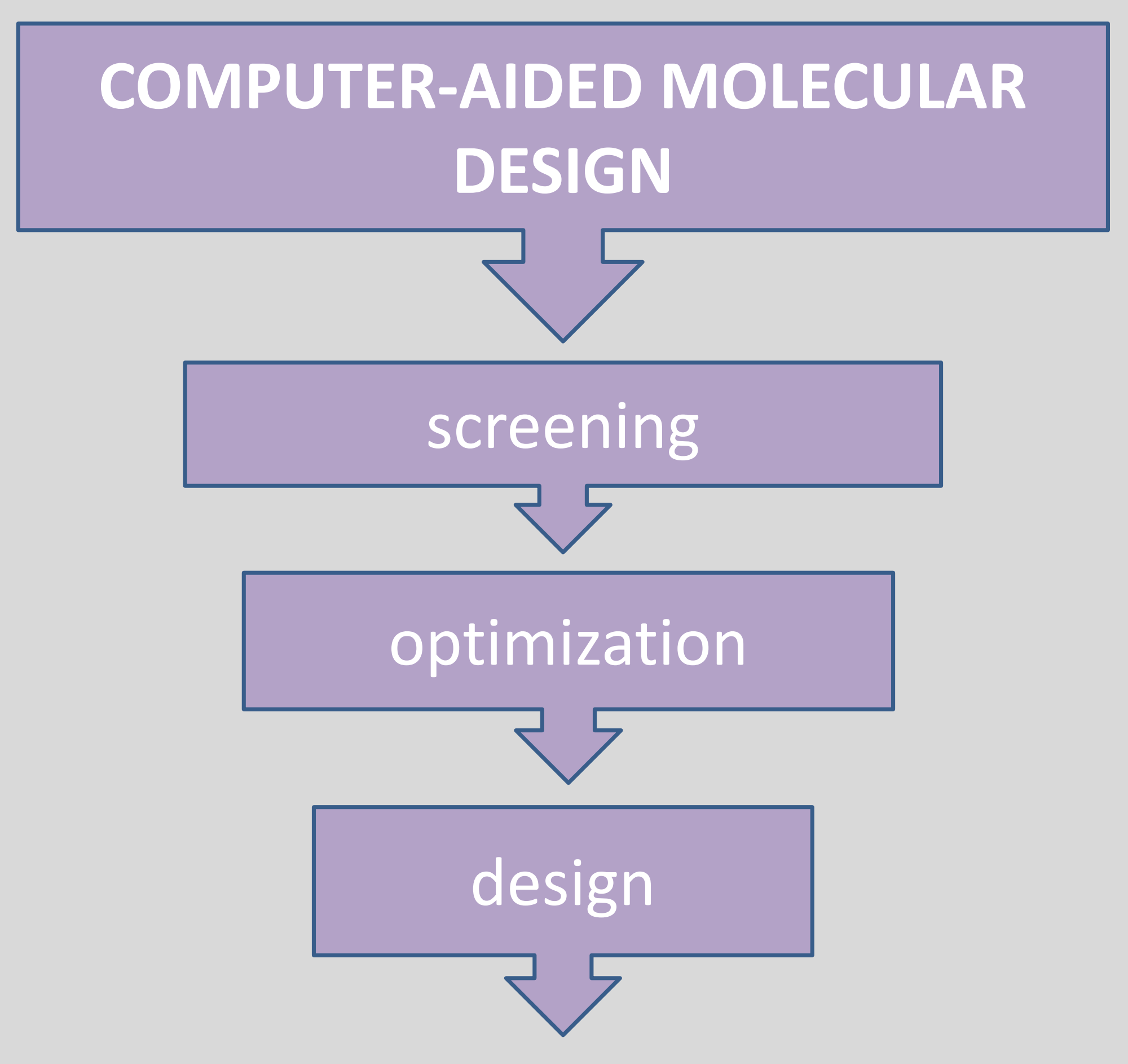

new potent agents in plant protection

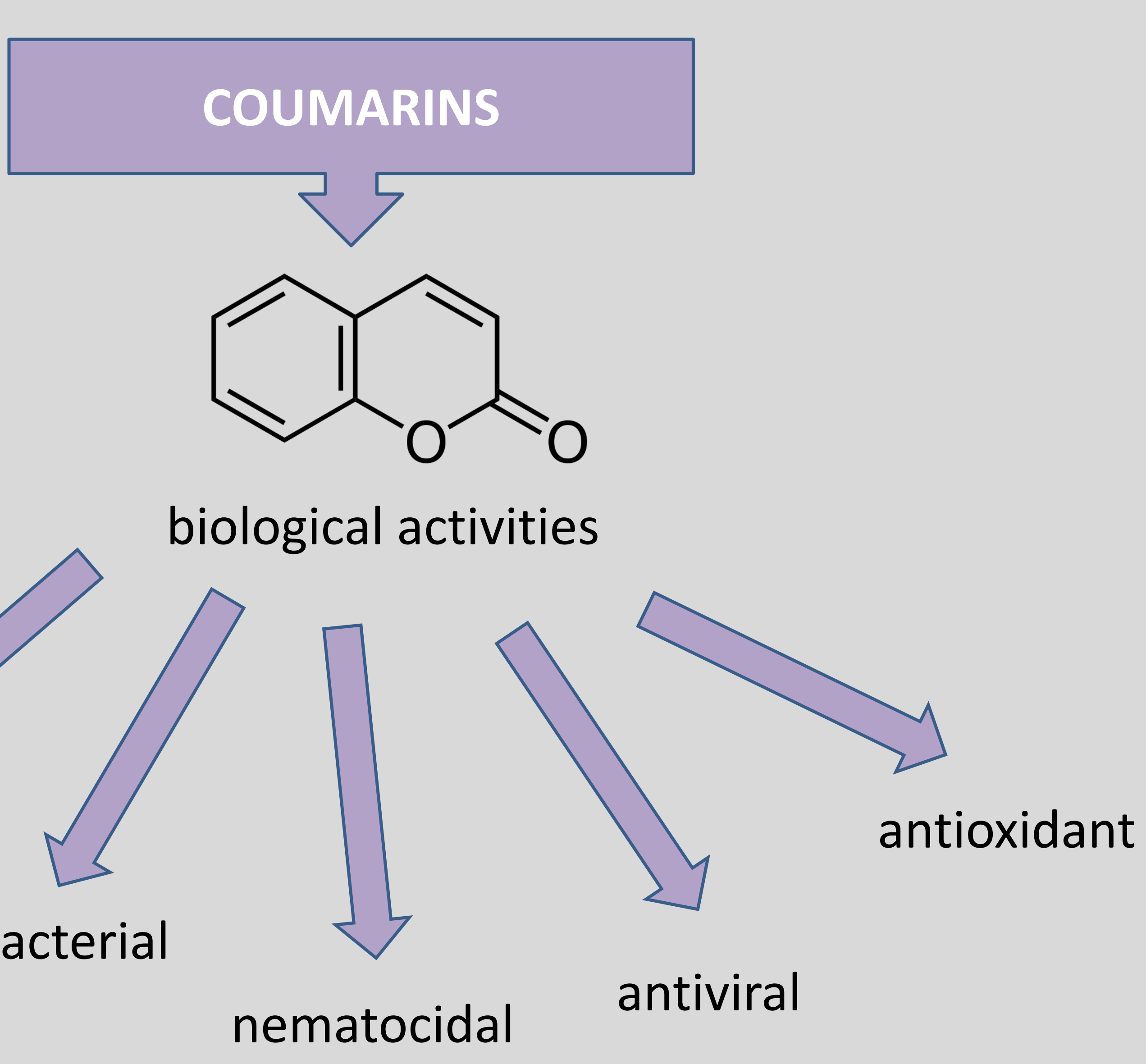

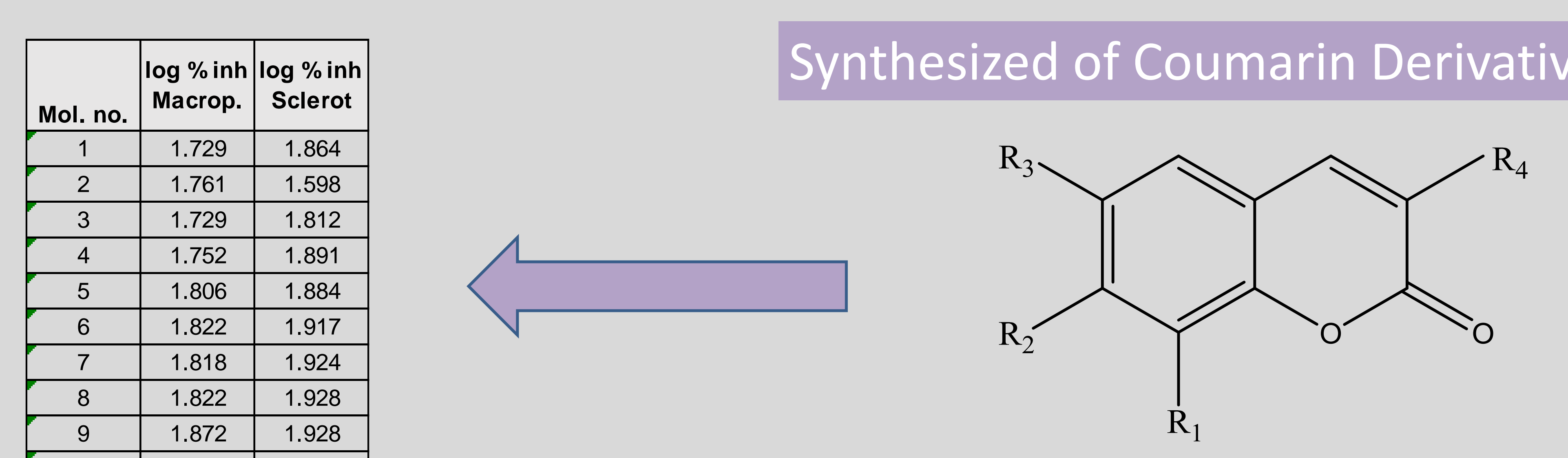

antifungal evaluation

(Macropomina phaseolina, Sclerotinia sclerotiorum)

Quantitative Structure Activity Relationship) QSAR

The artificial neural networks (ANN) analysis

\section{Results of ANN analysis}

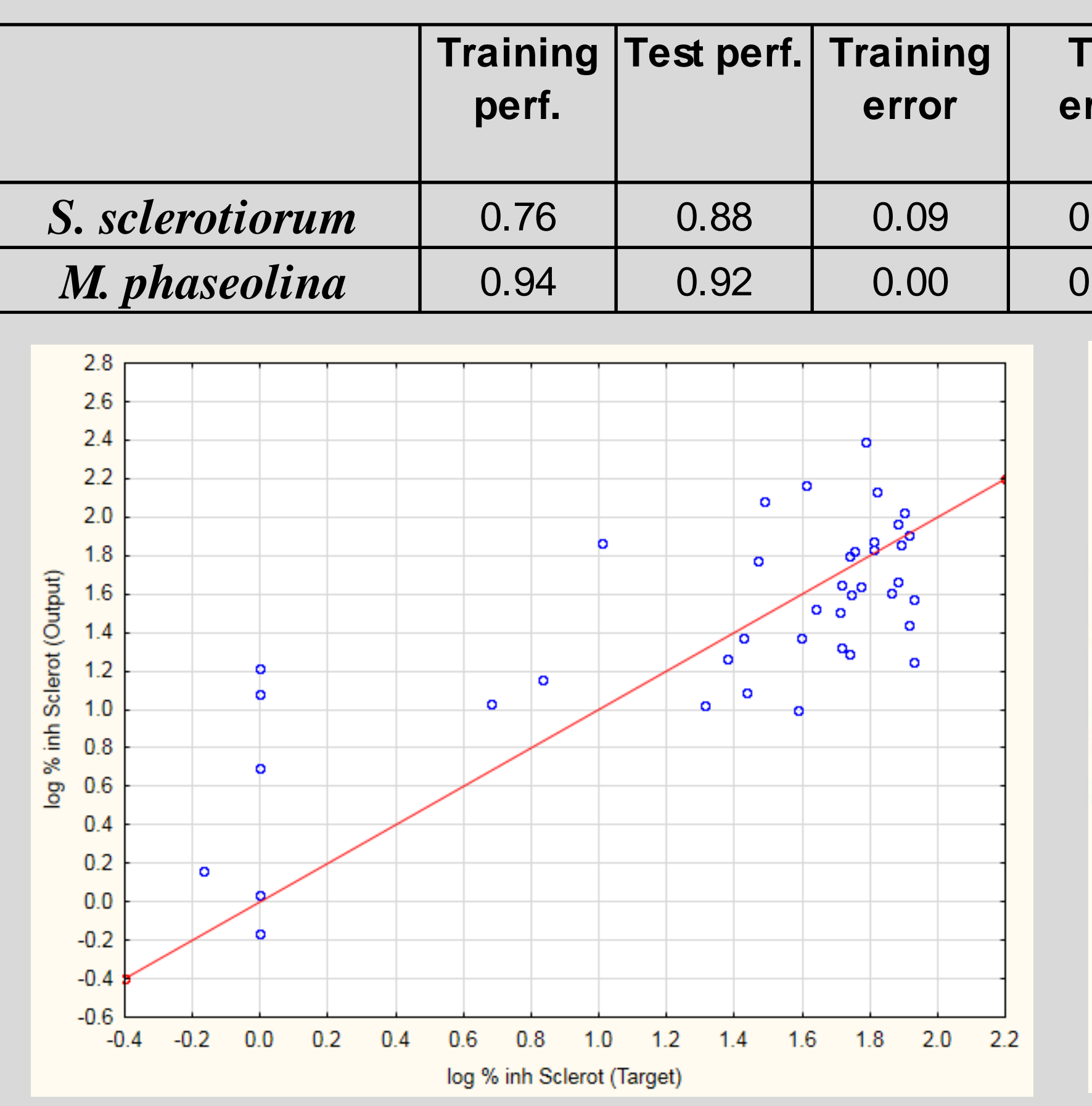

a)

\section{S. sclerotiorum}

Used molecular descriptors:

3D-MoRSE (Mor 19v); Moran autocorrelation (MATS7v); relative negative charge (RNCG AMI); and E-States, the sum of (- $\mathrm{CH} 2-)(\mathrm{Sss} C H 2)$,

\section{M. phaseolina}

Used molecular descriptors: geometrical symmetry (SYMM2); MATS4m; MATS5m; and sum of $(=\mathrm{C}<)(\mathrm{SdssC})$

Graphs of observed against calculated values using ANN models for:

a) Sclerotinia sclerotiorum;

b) Macropomina phaseolina.

\section{Conclusions:}

- relationship between the structures of coumarine and antifungal activity is not linear

- ANN could be performed for further research of more effective coumarin agents against the pathogen fungi.

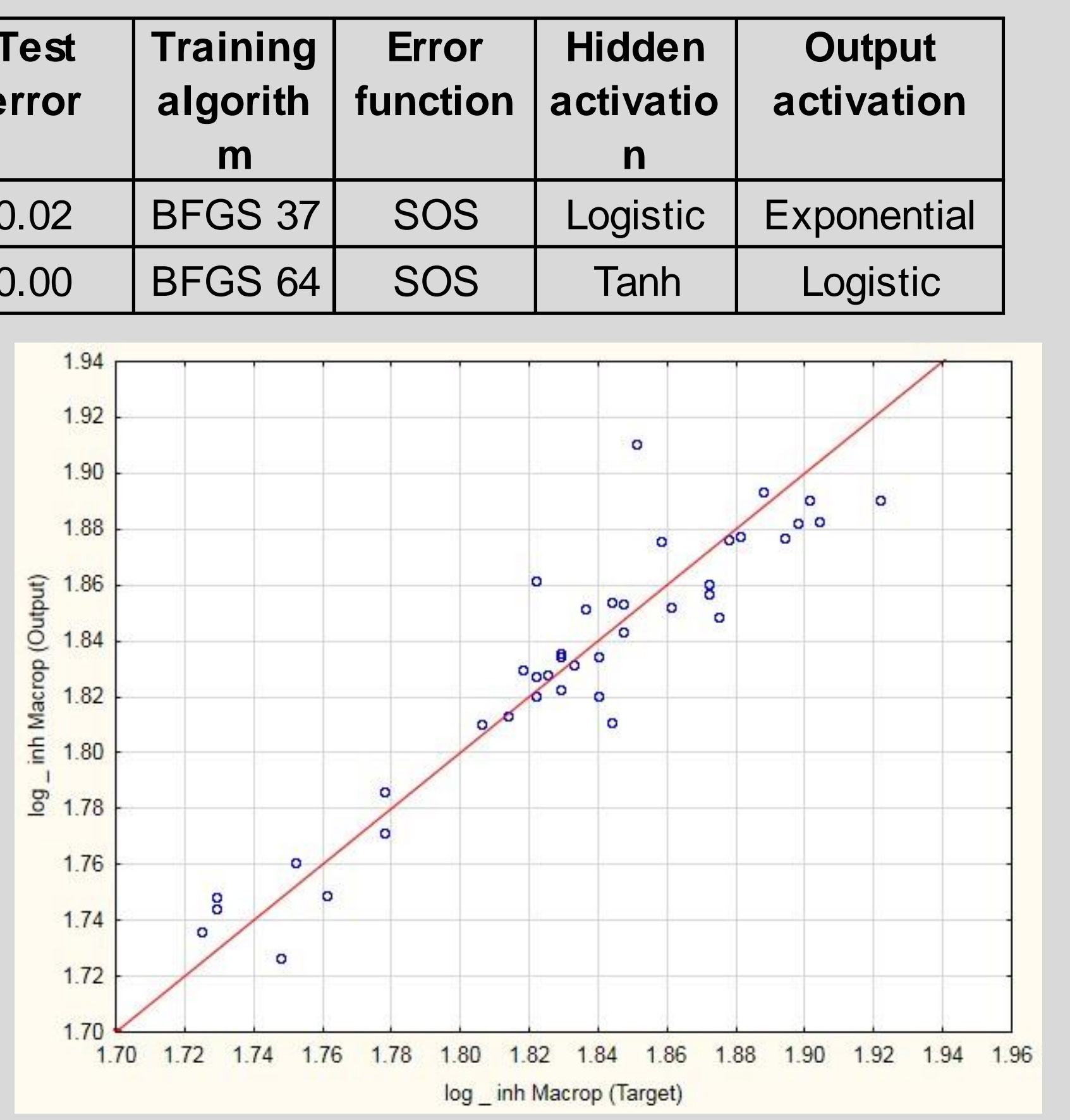

b)

\section{Literature:}

Melita Lončarić, Martina Sušjenka, Maja Molnar, Current Organic Synthesis, 2020, 17, 98-108 